\title{
biblio.ugent.be
}

The UGent Institutional Repository is the electronic archiving and dissemination platform for all UGent research publications. Ghent University has implemented a mandate stipulating that all academic publications of UGent researchers should be deposited and archived in this repository. Except for items where current copyright restrictions apply, these papers are available in Open Access.

This item is the archived peer-reviewed author-version of:

\section{REFRAMING CURRENT DEBATES ON YOUNG PEOPLE'S ONLINE PRIVACY BY TAKING INTO ACCOUNT} THE CULTURAL CONSTRUCTION OF YOUTH

Tom De Leyn

Ralf De Wolf ${ }^{1}$

Mariek Vanden Abeele ${ }^{2}$

Lieven De Marez

'Ghent University, Belgium Research group Media, Innovation and Communication Technologies (imec-mict-UGent)

${ }^{2}$ Tilburg University, The Netherlands

Tilburg School of Humanities and Digital Sciences

In: $\quad$ Proceedings of the 10 ${ }^{\text {th }}$ International Conference on Social Media and Society, 174-183, 2019.

URL: $\quad$ https://dl.acm.org/citation.cfm?doid=3328529.3328558

To refer to or to cite this work, please use the citation to the published version:

De Leyn, T., De Wolf R., Vanden Abeele, M. M. P., \& De Marez, L. (2019). Reframing Current Debates on Young People's online Privacy by Taking into Account the Cultural Construction of Youth. Proceedings of the $10^{\text {th }}$ International Conference on Social Media \& Society, 174-183. Toronto, ON, Canada: Ted Rogers School of Management. DOI: https://doi.org/10.1145/3328529.3328558 


\begin{abstract}
In public discussions regarding online privacy, young people are oftentimes portrayed as individuals who put themselves and others at risk with their naive and reckless online behavior. Recent scholarly work, however, debunked the myth that teenagers do not value privacy anymore by uncovering how they manage sensitive information in their everyday life. In this paper we argue that underlying assumptions of this scholarship still hinder our understanding of youth's engagements with social media and privacy. First, researchers tend to reproduce an image of young people as 'unfinished'. Second, studies fail to account for young people's exposure to technopanic narratives. Finally, the scholarship is oftentimes grounded in a liberal idealization of privacy as something inherently desirable for young people. To critically reflect upon these assumptions, we suggest taking into account the cultural construction of youth. Specifically, we argue that youths' experiences as "beings-inthe-present", society's anxieties about a digital future, and power dynamics might be essential elements that mediate young people's engagements with social media, privacy, and society.
\end{abstract}

\title{
CCS CONCEPTS
}

\section{- Security and Privacy $\rightarrow$ Social aspects of security and privacy KEYWORDS}

Culture, privacy, social media, technopanic, youth

\section{ACM Reference format:}

Tom De Leyn, Ralf De Wolf, Mariek M.P Vanden Abeele and Lieven De Marez. 2019. Reframing Current Debates on Young People's Online Privacy by Taking into Account the Cultural Construction of Youth. In Proceedings of the International Conference on Social Media \& Society, Toronto, Canada (SMSociety). DOI: https://doi.org/10.1145/3328529.3328558

\section{INTRODUCTION}

The advent of social media and its widespread adoption by young people has led to paradoxical concerns among parents, educators, scholars, and the general public with regard to youth's online privacy $[1,2]$. On the one hand, there are fears that youths are at a greater risk of becoming victims of tech-savvy predators and commercial data driven companies $[1,2,3,4,5]$. On the other hand, there are concerns that young people themselves erode the notion of privacy by acting 'unfiltered' on social media and by being too connected to a digital world while being too detached from their physical surroundings and relations $[1,2,3,6,7,8,9]$.

Interestingly, the perception of youth as both potential victims of the dangers presented by media technologies and as perpetrators engaging in 'deviant' online behaviors are grounded in the same assumption. Namely that youth lack 'adult' rationality and responsibility and are subsequently 'at risk' when they go online $[1,10,11,12]$. This assumption has given rise to widespread "technopanics"about young people's media use [2, 13]. These technopanics produce tensions between youth and the adult institutions - such as the family and the education system - that structure their experiences because they fuel the rhetoric that adults have the right to intervene in the lives of the young in order to guide and protect them while simultaneously justifying youths' exclusion from networked public life $[1,2,5,14,15,16]$. 
Although it is true that social media hold a central place in young people's lives and that their participation in networked environments is not risk-free, researchers who pay attention to the voices and experiences of young people show that the technopanics portraying youth as irrational and irresponsible are a far cry from a more nuanced reality $[5,13,17,18,19,20]$. Rather than appropriating social media in a random or non-reflective manner, youths recognize and utilize these technologies as a valuable resource in their everyday life. In particular, young people's media technology adoptions facilitate their trajectories into adulthood [20]. Youth's networked participations enhance their efforts to socialize, build and explore identities, gain autonomy, and, by large, consolidate a place in the world [17, 19, 20, 21, 22, 23]. In doing so, youth do not automatically give up their privacy - as is often assumed in the public debate [3]. However, the privacy practices of young people develop and take form in the context of a youth culture, which adults have limited access to [20,24]. As a result, adults often fail to see and understand the myriad of ways teenagers negotiate privacy in their everyday life. Over the past few years, several studies have debunked the stigmatizing myth that young people do not value privacy anymore, sometimes even suggesting that they are more capable of protecting their privacy than adults [e.g., 3 , $4,6,24,25,26,27]$.

By providing a nuanced and evidence-based counterargument to the dominant debate about young people's social media use, this scholarly work has already made important steps in deepening our understanding of the interactions between youth, society, and technology. We argue, however, that we also need to critically reflect on this body of scholarship, as it includes certain assumptions that might impede our understanding of young people's privacy experiences. Based on our collective knowledge of the fields of communication sciences and anthropology, we identify and reflect on three common perspectives in the academic literature on youth's online privacy. A first assumption we observed is the unintentional reproduction of the image of young people as 'unfinished beings' [11, 12, 14, 15]. Secondly, there is often a lack of attention given to how youth's experiences are shaped by their exposure to technopanic narratives [e. g., 3, 6, 28, 29]. Finally, the general assumption that privacy is something inherently good that young people should maintain, obscures various power dynamics stemming from the concept's liberal foundations $[30,31,32]$.

To address these assumptions, we suggest moving beyond a gaze that emphasizes adolescent development and socialization. We put forward a cultural perspective that examines youths as "beings in the present" [11], society's anxieties about a digital future and the interplay between various power dynamics. Only then can we truly avoid technopanics and deterministic observations, and include young people's voices and engagements with social media, privacy, and society.

\section{YOUTH AND ONLINE PRIVACY}

\subsection{Technopanics}

The omnipresent role of media technologies poses new benefits, but also new challenges [33]. Many of these challenges concern how people can maintain privacy in online environments. For example, the networked nature of social media challenges its users to know who has access to what information $[1,24,33]$, leads to a gathering of multiple audiences that collapses contexts - making it harder to pinpoint which social norms apply when disclosing information - $[1,34,35]$, and requires a constant reflectivity over content that is persistent, searched, 
and copied $[1,36]$. Moreover, the accumulation of digital traces by companies and governments confronts us with an organized form of panoptic surveillance, which institutionalizes the erosion of privacy $[33,37,38]$.

Considering the challenges that media technologies such as social media pose for retaining privacy, it is not surprising that youth's networked behaviors ignite concerns. However, these concerns easily take the form of a technopanic [2]. In a technopanic, both social media and young people's behaviors are demonized by overemphasizing and exaggerating the actual risks stemming from youth's networked participation [2]. This leads to a moral panic that is constituted of dystopian narratives concerning how youth's engagement with social media are a threat to not only their own wellbeing but also the common good $[1,2,4,39]$.

The foundations of these dystopian technopanics are relevant to explore as these narratives reveal the implicit assumptions that society has of young people. These societal dogmas subsequently inform people's evaluation of, and reaction to, youths' online behavior. If we explore these dystopian narratives, we can see that they are instructed by two types of beliefs that are undergirded by a similar implicit assumption about youths. First, there is the belief that young people are at a higher risk of being victimized as their behavior in online environments makes them susceptible to harmful effects of media exposure $[1,40,41]$. Barnes' seminal work on the "privacy paradox" reflects this belief. She argued that youths disclose personal information unconsciously and do not care about the public nature of social media [37]. The assumption that young people's naivety and lack of responsibility puts them at risk was to a limited extent supported by some studies claiming that young people lack the required cognitive skills to grasp the risks of online participation $[42,43,44,45]$.

A second, related belief concerning young people, social media and privacy is that youths' irresponsible and irrational online behavior is in itself a risk for the survival of privacy as a cherished value of society $[1,2,4,6]$. New York Magazine, for example, recently featured a series of articles under the umbrella title "Kids, the Internet, and the End of Privacy" [46]. Articles such as these voice anxieties that the popularity of social media among young populations could disrupt 'physical' sociality and could cause the disappearance of privacy due to young people's 'reckless' and 'naive' propensity for favoring online disclosure $[3,6,7]$.

To date, beliefs that young people risk becoming victims of privacy-related crimes and simultaneously threaten eroding the very notion of privacy itself due to their reckless behavior are still visible in contemporary public discourses on youth and online privacy [4].These assumptions produce a "protectionist approach"in which adults privilege themselves with imposing restrictions in order to 'protect' youths against media technologies and themselves, effectively further excluding youth from public life $[1,2,41]$.0ver the past few years, however, scholarship has countered the portrayal of young people as passive, naive, irresponsible, or irrational human beings [e.g., 3, 6, 24, 26, 27, 47, 48]. Rather, the dystopian technopanic narratives are a one-sided representation of a more nuanced and complex reality.

\subsection{Online Privacy}

Contrary to technopanic narratives that fear the 'end of privacy', scholarship devoted to the relationship between youth, social media and privacy provides compelling evidence that the value of privacy is not lost on the young $[6,24,49]$. By paying close attention to young people's voices and experiences, scholars uncovered the myriad of ways teenagers actively manage their privacy $[6,24,49]$. The bulk of these studies is built on the theoretical foundations of Altman [50] and Petronio [51], who emphasize the importance of negotiating boundaries around 
the self. Several studies demonstrate how youths use privacy settings to limit access to personal information [e.g., 25, 28, 49, 52]. Some point towards more creative tactics that young people employ in order to control the social situation, such as posting contents of which the double-layered meaning can only be deciphered by certain intimi who have background knowledge [i.e., "social steganography"] [e.g., 4, 6, 24]. Other research designs examine both means of control [e.g., 26, 27, 29, 53].

Although these studies illustrate that youths voice concerns and protect their privacy, some scholars suggest that young people pay more attention to "social privacy"than "institutional privacy" [1, 3, 6, 25, 29, 47, 53, 54]. Raynes-Goldie [29] conceptualizes social privacy as concerns over the protection of the private self against 'outside' influences in one's environment. People will try to shield themselves from suppression of their expression of identity and will try to conceal sensitive information regarding daily life. Institutional privacy, on the other hand, is in reference to a person's anxieties about how forces such as governments and companies aggregate data and abuse it for profit [29]. Although it has been suggested that there are generally less adequate options to control institutional privacy [55], the observation that youths are more inclined to use social privacy strategies has often been explained through the lens of young people's developmental life stage [e.g., 3 , $6,28,49,52]$.

According to these perspectives, youth's social media behaviors support their cognitive and social development. Consequently, the challenge for teenagers lies in balancing their desire for disclosure with the need to keep certain information private in ways that optimally support their developmental goals [28, 53, 54]. Youths value the public nature of social media because it facilitates certain developmental tasks and enhances socialization processes, such as building relationships and gaining autonomy $[1,20]$. Maintaining privacy, however, is equally important in that context, as it is a way to bypass 'parental' surveillance, or serves as social capital in the peer group $[4,6,24]$. Youth thus value the public properties of networked technologies while they concurrently strive to retain privacy [1, 4, 54]. As Marwick and boyd [24] eloquently put it: "Young people try to be in public without always being public."

\section{CRITICAL QUESTIONS FOR YOUTH AND PRIVACY RESEARCH}

Although the scholarship on youth, social media and privacy has moved beyond dystopian technopanic representations of young people's networked actions, there remain some assumptions that impede our understanding of young people's privacy experiences and behaviors. We argue that it is necessary to critically interrogate these assumptions and put forward the following questions to stimulate the debate: (Q1) What are the cultural meanings attached to 'youth' and how do they influence our understanding of youths' privacy? (Q2) How are dystopian technopanic representations of young people's practices approached, regardless of whether they contain truth? And finally (Q3) Is privacy inherently 'good' and desirable?

In youth studies there is a call for a critical evaluation of scholars' adult-centric and problem-oriented approach to young people's practices [10]. We respond to this call for youth and privacy research by addressing the questions presented above. We argue that in the current scholarship the voice of youth is heard, but the cultural meanings attached to youth are generally disregarded; that technopanic narratives are refuted but not addressed; and finally that privacy management strategies are investigated, whilst not questioning its idealization. 


\subsection{Disregarding the Cultural Meanings Attached to Youth}

There is a tendency for the scholarship of youth, media technology, and online privacy to highlight developmental and socialization trajectories. In the process, scholars risk downplaying how young people's experiences are partially shaped by a society's cultural attributions of what youthfulness should entail. The literature on "mobile youth culture", for example, considers young people's online behavior as an "expression of collective experiences" that teenagers face when they transition from youth to adulthood [17, 19, 20]. In a similar vein, several studies analyzed young people's privacy management explicitly through the lens of their cognitive and social developmental life stage [e.g., 6, 29, 49, 52]. Although it is not always specified how scholars conceptualize youth, participant's age remains an important factor guiding the research questions. According to Honwana [56], analyzing certain phenomena through the lens of age implies the underlying assumption that young people are different from adults because of their 'transitional' life stage.

By emphasizing young people's transitions to adulthood, scholars risk reproducing an uncritical, modernist narrative in which youths have to walk through different stages of progress towards the normative stable goal of adulthood [12, 15]. In light of this, adulthood is culturally constructed as the "unmarked normal" or the "civilized state" of humanity in opposition to "the primitive state of childhood" and the "unruly barbarism of adolescence" [12]. Young people are therefore believed to be 'unfinished', resulting in unequal power and hierarchy relationships, which cause many of the tensions between youths and adults $[11,12,14,15,16,57]$.

The underrepresentation of a perspective that explicitly accounts for the tensions stemming from the cultural significations attached to youth is surprising considering that some of the most influential works on young people, media technologies and privacy mention the importance of doing so. In their early conceptualization of mobile youth culture Castells and colleagues [21] refer to various studies that illuminated the dynamics resulting from youth's cultural position in society $[58,59]$. Moreover, boyd's analysis of young people's participation on networked publics shows how youth's cultural position influences their technology use [1]. Specifically, their lower hierarchical status in relation to adults makes social media particular attractive for youth [1].

Although a perspective that considers the cultural dynamics of being young is sometimes implicitly addressed in scholarly work [e.g., 1, 4, 24, 25], these insights remain rather underexplored and are less addressed in the scholarship on the interactions between young people, social media and privacy. Therefore, some scholars identify the lack of a comprehensive lens to account for how youth's cultural position shapes their engagements with social media and privacy as a blind spot $[7,19,20,60]$.

\subsection{Overlooking the Interactions Between Youth's Media Use and Technopanics}

A second area of critical interrogation involves how technopanics are treated in the scholarship on young people's social media use and privacy. Technopanics often inspire research, serving as a background against which researchers can demonstrate how society holds misinformed beliefs about the dynamics between youth, society and technology. Findings typically present evidence that young people's presence in networked environments does not automatically imply that they give up privacy freely [e.g., 3, 6, 26, 27, 28, 29]. However, youth's exposure to these technopanic narratives and how they affect them in their engagements with social media are rarely considered in research designs. 
The importance of analyzing young people's exposure to and understanding of the technopanic surrounding their online behavior is illustrated by boyd and Marwick who examined the impact of adults' fear of online stranger danger on teenagers' online participation $[1,4,24]$. They observed how youths, especially girls, withdrew from networked publics because they internalized the anxieties produced by technopanics. Alternatively, meddling parents who are anxious due to technopanics stimulated some young people to hide aspects of their networked participation [4, 24]. In both cases, teenagers used expressions similar as those prevalent in technopanics to either explain why they are afraid of networked environments or as the basis for their critique on interfering adults $[1,4,24]$. This shows that youths themselves internalize and reproduce the technopanic discourses to which they are exposed.

Considering these observations, we may conclude that technopanics influence how youths experience social media and privacy; potentially in ways that they perceive their own agency to protect and negotiate their privacy online as limited. As young people may not understand nor affiliate with the 'adult' way of regulating online privacy, they may feel coerced to withdraw from, rather than participate in, youth culture on social media. Moreover, they may reproduce anxieties over privacy-related dangers. Given the far-reaching consequences that exposure to these technopanics may have, it is essential that future work incorporates in-depth explorations of how young people perceive and act upon such negative narratives.

\subsection{The Idealization of Liberal Privacy}

A third assumption informing research on youth, social media and privacy that impedes our understanding of young people's privacy experiences reflects the ideological value attributed to privacy. In general, research designs propose a conceptualization of privacy as something inherently good that young people seek to maintain. Although these studies provide insights to how youths manage their personal information, it is seldom interrogated whether society's hegemonic notions of privacy, with its focus on control or access restriction, could be detrimental to young people's agency. Privacy management is often hailed as a necessary and beneficial goal in a digitalized world where governments, industries, and strangers could intrude at any moment through networked publics.

Such a liberal interpretation of privacy is critiqued by Fuchs, who proposes that contemporary western societies 'suffer' from "privacy fetishism" [31]. Based on critical scholars' arguments that the automatically positive value attributed to privacy promotes "possessive individualism that can harm the public good", Fuchs stresses how privacy can be evoked by the dominant elite to justify the status quo. [31]. Moreover, the emphasis on privacy as something that the individual could control overestimates people's freedom in choosing what they want to disclose by downplaying social, political, economic, and technological constraints [31, 32].

The concept of privacy fetishism thus reminds us that some individuals, groups, or institutions, may be more privileged and decide for themselves whether to keep information private [31,61]. According to Anthony and colleagues, privacy can be considered as a resource that intersects with inequality [30]. People with a lower hierarchical status experience a transfer of control over their privacy to 'others'; a process called "inclusive boundary coordination" by Petronio [51]. Having a disability or illness, for example, forces an individual to provide more information in exchange for healthcare [30]. It can be argued that children and youth are 'naturally' coerced into inclusive boundary coordination because society appoints to adults the power to regulate young 
people's lives $[15,51]$. This prompted some authors to examine how teenagers manage privacy in the context of adult surveillance $[4,24]$.

Although the above critiques of the dominant liberal notion of privacy calls into question the role of subversive capitalist forces and directs our attention to how inequality differentiates people's efforts to protect the private self, privacy mostly retains its idealized value as a virtuous 'goal'. Boyd, however, questions whether the contemporary importance attached to privacy is as innocent as it looks: "With an elevated and idealized view of privacy, we often forget the reasons that enslaved peoples desperately wished for access to public life" [1]. Moreover, a study on privacy in India and Brazil shows how privacy is evoked to limit and stigmatize young girls' public - online and offline - behavior [62]. In a similar vein, Locatelli [63] illustrates how women on Instagram combat the stigma of public breastfeeding by voicing critiques on the enforced 'private nature' of the motherchild care relationship in patriarchal society. The liberal and Eurocentric notion of privacy is also found to cause adverse effects on the social fabric of indigenous communities because it serves the purpose of reproducing western values [e.g. 64,65]. The common thread in these studies is how privacy intersects with morality, power, and inequality in such a way that the ideological concept of privacy itself discriminates against 'marginalized' populations.

Studies that illuminate the potential for privacy ideology to be used in an oppressive way and stress the importance of public participation in society are powerful reminders that our notions of and discussions about an idealized notion of privacy might function as powerful tropes, facilitating certain questions while simultaneously shutting our eyes and minds for others. This does not mean that concerns over the protection of personal information are not legitimate or that we should abandon efforts to examine privacy management altogether. Rather, we have to be attentive to how ideological dogmas about privacy might impede our ability to grasp some experiences of oppression related to media technologies. Therefore, we question whether the current scholarship's focus on privacy as a desirable goal is always warranted in the context of tensions between adult institutions and youth culture on social media. Instead of treating privacy as something that is naturally 'good', and as something that young people seek, we suggest it is important to examine how societal notions of privacy could possibly limit youth's agency in the public sphere.

\section{DISCUSSION: TAKING INTO ACCOUNT THE CULTURAL CONSTRUCTION OF YOUTH}

The scholarship on youth, social media and privacy has exposed the popularized belief that 'youth don't care about privacy' as a dystopian technopanic myth [66]. Young people's presence on social media does not automatically result in deviant behaviors that threatens their own privacy and that of others; rather, youths engage in privacy protection behaviors while performing media practices that support their biological and social transitions to adulthood. We argued, however, that some underlying assumptions instructing this scholarship still require critical interrogation to further deepen our understanding of the interactions between youth, social media and privacy.

In order to critically interrogate scholars' adult-centric and problem oriented approach to young people's privacy practices, this paper proposed three areas of interest that future research could address. First, we revealed that only a few studies incorporated a perspective that accounts for how cultural meanings attached to youthfulness mediate young people's media experiences. Secondly, we suggested uncovering how youths 
perceive and act upon technopanic narratives to stimulate more holistic insights about their engagements with social media and privacy. Finally, how ideological conceptions of privacy as something 'naturally' good that the individual should control interact with morality, power and inequality must be explored.

In an effort to inspire future research designs to include the above critical reflections, this paper recommends taking into account the cultural construction of youth. Such a cultural perspective recognizes that our biological and social experiences of 'being young' and 'being an adult' are partly mediated by a society's cultural conceptions of youth [15]. By placing the tensions between young people and adult institutions in particular as focal point of study $[11,15,57]$, the current debates regarding online privacy and youth can be necessarily reframed. The appropriation of a cultural lens to the study of youth's engagements with social media and online privacy, enables us to formulate three theoretical guidelines in which young people as "beings-in-the-present" [11], society's anxieties about a digital future, and power dynamics are addressed.

\subsection{The Cultural Construction of Youth: Theoretical Guidelines}

4.1.1 Beings-in-the-present. The first guideline of a cultural approach on youth formulates a direct critique on the tendency to examine young people's experiences through the lens of their transitions to adulthood. Instead of examining how youths are socialized and socialize themselves, studies could recognize young people as "beings-in-the-present" with their own identities and cultural practices that do not always represent a functional steppingstone for their future adult roles [11, 57]. Specifically, this guideline directs attention to the "here-and-now-moment" of youth by studying them as cultural agents in their own right who may voice important critiques on society and citizenship [57,67].

Recognizing the "here-and-now-moment" [67] of youth does not mean that their transitions to adulthood should be neglected in research. Rather, it necessitates the need to contextualize both developmental trajectories and young people's 'present' experiences within a cultural ecosystem [14]. On the one hand, youths' pasts, presents and futures are shaped by societal and technological structures [11]. The education system, for example, can be said to represent a concrete manifestation of how the life course is imagined through linearity [16]. Moreover, social media, such as Facebook, perpetuate the experience of linearity by confronting people with a chronological structure and showing them 'memories' from the past. Brandtzaeg and Lüders [68] found that this confrontation causes a "time collapse"in which young people feel embarrassed by their seemingly 'younger' selves. On the other hand, youths act upon these structural forces as cultural agents and have proven to be highly influential in how society and technology takes shape [11]. For example, the popularity of mobile technology in its current form is suggested to be the result of young people's creativity and agency [21].

4.1.2 Bearing the Burden of a Digital Future. A society's projection of fears and hopes about its own transformation on the body of the young can also account for how youth's experiences are culturally influenced $[15,57]$. Young people can be considered a personification of the future upon whom societal structures attempt to instill culturally appropriate behaviors and values [16]. This is done in order to ensure a society's future potential as well as avoiding dystopian social change [16]. In this process, young people's experiences are often "constructed from the outside and from above" in the generalized notion of 'generations' as both antidotes and pathologies for the challenges presented by perceived rapid societal transformations $[11,14,15,16,57]$. 
Concerning the hopes and anxieties surrounding a digital future, youth are often lumped together under the contemporary generational term of "digital natives"[66]. The digital native conjures the image of the tech-savvy teenager who grows up in a networked world that is remarkably different than the reality of generations preceding them [43]. The generational categorization of digital natives marks an imaginary divide between youths and adults that represents utopian, as well as dystopian, visions about the digital future. Although young people are portrayed as technologically skilled, they are also seen as more susceptible to contemporary and future media manipulations such as fake news, data breaches, and filter bubbles $[15,13,56,69]$.

Symptomatic of this generational classification is how adult institutions, most notably the education system, will try to 'guide' youth in an adult-biased direction while simultaneously neglecting and suppressing the realities of youth culture [16]. Moreover, Christiansen and colleagues suggest that youths could appropriate generational divisions, such as the digital native, by "inhabiting, escaping and moving" within their culturally ascribed position "in meaningful ways"[14].

4.1.3 Power Dynamics. The third guideline that can be derived from a cultural perspective on youth is that future research needs to account for how the cultural categorization of youth naturalizes the (re)production of hierarchy, power, dependency, difference, and sameness in the minds and on the bodies of the young $[14,15,16]$. According to cultural theories of youth, the processes of modernity do not only concern the institutionalization of age but also the widespread marginalization and exclusion of young people based on cultural assumptions [15]. Most notably is the belief that youths are "people in the process of becoming" guided by irrational and primitive impulses while adulthood is seen as the "unmarked normal against which deviations are marked out" $[11,12]$. Because being young is perceived as a temporary 'unfinished' life stage in which people have to undergo certain developmental and socialization processes, adults occupy the higher moral ground in society as supposedly 'finished beings' [12].

The inferior position of young people is, according to cultural theories, a key factor in shaping the experience of being young. The condition of youth is thus not only situated in the transformative process of growing up. It is also a constant negotiation of power in which young people occupy a liminal space between exclusion and inclusion, restrictions and freedom $[11,14,16,56]$. Perspectives that treat youth as a cultural construction look at how they experience and act upon the sometimes contradictory forces of the nation-state, market, household and education system who all seek to exert influence on its young 'targets' [11, 15, 16]. Accordingly, cultural theories explore how youths navigate the social reality by simultaneously conforming to and defying their hierarchical position in society $[11,14,56]$.

\subsection{Avenues for Research on Youth's Online Privacy}

Having outlined three broad theoretical guidelines to account for the cultural experience of being young, this paper concludes with some concrete avenues for research into youth's social media use and experiences of online privacy. In light of this, it is noteworthy that several authors observed that media technologies bestow young people with new found power in reclaiming agency $[1,11,14,16,21]$. Social media, for example, enables youths to break free from restricted socialization spaces appointed by society [1, 2, 21]. However, more research is needed to understand how they voice critiques on society through social media; how adult institutions try to 
(re)gain control over these networked 'youth spaces'; and how young people harness the affordances of social media in their negotiation of power.

Examining how technopanics play a central role in the tensions between young people and adult institutions is a first possible area of interest when considering the dynamics between youth, social media and privacy. For example, these panic-driven narratives may produce interventions to direct youths to reproduce normative 'appropriate' behaviors. In a study of Chinese youth's negotiation of 'proper' internet use, Liu conceptualized these normative 'appropriate' behaviors as the "proper wired self" [70]. In accordance with Liu's observation of how a society's moral rules affect youth's networked behaviors [70], we suggest future studies to analyze how hegemonic privacy discourses might affect online youth culture. On the one hand, the scholarship that integrates the cultural construction of youth could explore whether these narratives limit young people's agency. On the other hand, scholars may uncover how youths negotiate their hierarchical status in society by incorporating and/or rejecting normative privacy standards in their own privacy management.

Second, and related to the concept of a proper wired self, a cultural perspective of youth stresses the importance of exploring whether the ideological value of privacy is related to the notion of "social adulthood". Social adulthood refers to the attainment of normative characteristics that a culture associates with maturity $[56,71]$. Youths are only 'accepted' as full-fledged members of society and rewarded with greater privileges when they acquire features of social adulthood - a process through which social and cultural reproduction is assured $[56,71,72]$.

If privacy is a defining trait of contemporary social adulthood, achieving an adult-centric understanding of privacy could be a pathway for young people to gain social and cultural capital that increase their power position in society. Alternatively, hegemonic notions of privacy could also be evoked by adults to distinguish themselves from youths, and as a result, restore and maintain their morally superior position that was disturbed because of digital natives' presumed technological mastery. Therefore, this paper argues that analyzing youth's media use through the lens of privacy as a normative feature of social adulthood might deliver fruitful insights in the dynamics between young people, technology, privacy and society. Specifically, scholars should investigate youth's critiques on hegemonic notions of privacy and how they try to bridge the power divide between them and adults by conforming to, as well as defying, cultural expectations of adult-centric privacy management.

Although the concepts of a proper wired self and social adulthood seem to be relevant for reframing current debates on youth's online privacy, a perspective that incorporates the cultural construction of youth might be better understood as a guide to critically reflect upon one's own assumptions and knowledge when conducting research. The cultural construction of youth does not come with certain principles that needs to be strictly followed. Rather, it calls for and facilitates different questions and approaches to uncover how young people experience privacy. Youth's perception of their representation in the public discourse is, for example, a research topic that might further deepen our understanding of how their cultural position affects the interactions between young people, social media, privacy and society. Moreover, we argue that the holistic nature of ethnographic research might be an adequate approach to study youth's online privacy from a cultural perspective. According to Herzfeld, ethnography is able to capture the complexity of social realities [73]. Therefore, we argue that ethnographic studies will be suitable to account for the multiple layers of societal and technological structures that are imposed on youths while simultaneously acknowledging their agency. 


\section{CONCLUSION}

As is often the case when society fears its own transformation [57], youths seem to be at the center of the debates and controversies surrounding social media and online privacy. Although concerns about privacy and surveillance are not illegitimate in contemporary data-driven society, these discussions often acquire the characteristics of a technopanic [2]. On the one hand, the negative consequences of new technologies are exaggerated while their beneficial potential for youth culture is ignored [2]. On the other hand, cultural assumptions about a linear pathway to adulthood constructs young people as reckless and irrational who are potential victims of privacy invasion as well as perpetrators who forsake privacy $[1,2,3,4,5,6,7,8,9]$. The scholarship on youth and online privacy, however, illustrates that young people are concerned about privacy and are actively protecting their personal life worlds. Studies scrutinizing the privacy practices embedded in youth culture thus are essential in debunking persisting myths about young people's social media use.

Although the scholarship on youth and online privacy is essential in granting us nuanced knowledge of young people's privacy practices, we argued that it is necessary to critically reflect upon this body of literature in order to further interrogate "misconceptions that constitute dangerous commonsense" about youth's networked behaviors [7]. These reflections suggest, for example, that scholars often conceptualize young people as being situated within a temporary transitional life stage. Privacy research therefore does not escape cultural assumptions about youth by identifying them as exceptionally different than adults. Furthermore, the interactions between technopanics and young people's media use are seldom explored. The observations of boyd and Marwick $[1,4,24]$ illustrate the urgency to include these dynamics in future research designs. Finally, our reflections point towards the tendency of the scholarship on youth and online privacy to uncritically idealize privacy. Instead of interrogating hegemonic notions of privacy, the concept is often treated as something that should be desirable for young people engaging on social media. Several scholars found, however, that the liberal concept of privacy intersects with inequality and normativity which disadvantages subaltern subjects $[1,62,63$, $64,65]$.

The critical reflections made in this paper call for a reframing of current debates on youth's online privacy. We suggested integrating a perspective that accounts for the cultural construction of youth. Such a perspective proposes three theoretical guidelines to keep in mind while conducting research. Scholars could 'interrogate our assumption of young people as unfinished beings by recognizing them as cultural agents who are not only shaped by but also shape encompassing structures'; 'account for how imaginations of a digital future interacts with youth's privacy experiences and management'; 'and explore how young people move through the social reality by complying to and challenging their cultural attributed power position in society'. By doing so, the scholarship on youth, media technology and online privacy might discover a whole spectrum of social media practices in which young people envision their rightful place in public life. 
De Leyn, T., De Wolf R., Vanden Abeele, M. M. P., \& De Marez, L. (2019). Reframing Current Debates on Young People's online Privacy by Taking into Account the Cultural Construction of Youth. Proceedings of the $10^{\text {th }}$ International Conference on Social Media \& Society, 174-183. Toronto, 0N, Canada: Ted Rogers UNIVERSITEIT GENT School of Management. DOI: https://doi.org/10.1145/3328529.3328558

\section{ACKNOWLEDGMENTS}

The authors would like to thank the anonymous reviewers for their valuable feedback. The research leading to these results has received funding from the Research Foundation - Flanders (FWO), under grant agreement number G048618N.

\section{REFERENCES}

[1] danah boyd. 2007. Why youth (heart) social network sites: The role of networked publics in teenage social life. In D. Buckingham (eds.), MacArthur Foundation Series on Digital Learning - Youth, Identity, and Digital Media Volume. MIT Press, Cambridge, MA.

[2] Alice E. Marwick. 2008. To catch a predator? The Myspace moral panic. First Monday 13, 6 (June. 2008), 1-22. D0l: https://doi.org/10.5210/fm.v13i6.2152

[3] Denise E. Agosto and June Abbas. 2017. "Don't be dumb- that's the rule I try to live by": A closer look at older teens' online privacy and safety attitudes. New Media and Society 19, 3 (September 2015), 347-365. DOI: $10.1177 / 1461444815606121$

[4] danah boyd. 2014. It's complicated: The social lives of networked teens. Yale University Press, New Haven.

[5] Sonia Livingstone. 2006. Opportunities and constraints framing children and young people's internet use. In M. Consalvo (Eds.), Internet Research Annual Volume 4. Peter Lang, New York, NY. 59-75.

[6] Claire Balleys and Sami Coll. 2017. Being publicly intimate: teenagers managing online privacy. Media, Culture and Society 39, 6 (November, 2016), 885-901. D0I: 10.1177/0163443716679033.

[7] Gerard Goggin. 2013. Youth Culture and mobiles. Mobile Media and Commun. 1, 1 (January, 2013), 83-88. DOI: $10.1177 / 2050157912464489$

[8] Sherry Turkle. 2011. Alone together: why we expect more from technology and less from each other. Basic Books, New York, NY.

[9] Jean M. Twenge, Gabrielle N. Martin and Keith W. Campbell. 2018. Decreases in psychological well-being among American adolescents after 2012 and links to screen time during the rise of smartphone technology. Emotion 18, 6 (January 2018), 765-780. D0l: http://dx.doi.org/10.1037/em00000403

[10] Mary Bucholtz. 2002. Youth and Cultural Practice. Annu. Rev. Anthropol31, 1 (November 2002), 525-552. DOI: 10.1146/annurev.anthro.31.040402.085443

[11] Filip De Boeck and Alcinda Honwana. 2005. Makers $\&$ Breakers: children $\&$ youth in postcolonial Africa. Currey, Oxford, UK.

[12] Deborah Durham. 2017. Elusive Adulthoods: Introduction. In D. Durham and J. Solway (eds.), Elusive Adulthoods: The anthropology of new maturities. Indiana University Press, Bloomington, Indiana.

[13] Sonia Livingstone. 2018. Audiences in an age of datafication: critical questions for media research. Television and New Media 20, 2 (November 2018), 170-183. D0I: https://doi.org/10.1177/1527476418811118

[14] Catrine Christiansen, Mats Utas, and Hendrik E. Vigh. 2006. Navigating Youth, Generating Adulthood: Social Becoming in an African Context. Elanders Gotab AB, Stockholm, Sweden.

[15] Jennifer Cole and Deborah Durham. 2007. Introduction: Age, Regeneration and the Intimate Politics of Globalization. In J. Cole and D. Durham (eds.), Generations and globalizations: youth, age, and family in the new world economy. Indiana University Press, Bloomington, Indiana. 
[16] John Comaroff and Jean Comaroff. 2005. Children \& Youth in a global era. In F. De Boeck and A. Honwana (eds.), Makers \& Breakers. Children $\&$ Youth in postcolonial Africa. Currey, Oxford, UK.

[17] Scott W. Campbell and Yong Jin Park. 2008. Social Implications of Mobile Telephony: The Rise of Personal Communication Society. Sociology Compass 2, 2 (March 2008), 371-387. D0I: 10.1111/j.17519020.2007.00080.x

[18] Eija-Liisa Kasesniemi and Pirjo Rautiainen. 2002. Mobile culture of children and teenagers in Finland. In J. E. Katz and M. Aakhus (eds.), Perpetual contact. Mobile communication private talk, public performance. Cambridge University Press, New York, NY.

[19] Mariek M. P. Vanden Abeele (2012). Me, myself, and my mobile phone. Status, identity and belongingness in mobile youth culture. Ph.D dissertation, KUL, Leuven, Belgium.

[20] Mariek M. P. Vanden Abeele. 2016. Mobile youth culture: A conceptual development. Mobile Media $\varepsilon$ Commun. 4, 1 (August 2015), 85-101. D0l: 10.1177/2050157915601455

[21] Manuel Castells, Mireira Fernandez-Ardevol, Jack Linchuan Qiu and Araba Sey. 2007. Mobile communication and society: A global perspective. MIT Press, Cambridge, MA.

[22] Rich Ling. 2010. Texting as a life phase phenomenon. Journal of Computer-Mediated Communication 15 (January 2010), 277-292. D0I: https://doi.org/10.1111/j.1083-6101.2010.01520.x

[23] Zheng Yan. 2018. Child and Adolescent Use of Mobile Phones: An Unparalleled Complex Developmental Phenomenon. Child Development 89, 1 (May 2017), 5-16. D0l: 10.1111/cdev.

[24] Alice E. Marwick and Danah boyd. 2014. Networked privacy: How teenagers negotiate context in social media. New Media \& Society 16, 17 (July 2014), 1051-1067. D01: 10.1177/1461444814543995

[25] Danah boyd and Esther Hargittai. 2010. Facebook privacy settings: who cares? First Monday15, 8 (August 2010), 265-288. D0l: https://doi.org/10.5210/fm.v15i8.3086

[26] Ralf De Wolf, Koen Willaert and Jo Pierson. 2014. Managing privacy boundaries together: Exploring individual and group privacy management strategies in Facebook. Computers in Human Behavior 35 (June 2014), 444-454. DOI: https://doi.org/10.1016/i.chb.2014.03.010

[27] Ralf De Wolf. 2016. Group privacy management strategies and challenges in Facebook: A focus group study among Flemish youth organizations. Cyberpsychology: Journal of Psychosocial research on Cyberspace 10, 1, article 5, 16 pages. D0I: 10.5817/CP2016-1-5

[28] Emily Christofides, Amy Muise and Serge Desmarais. 2009. Information Disclosure and Control on Facebook: Are They Two sides of the Same Coin or Two Different Processes? CyberPsychology \& Behavior 12, 3 (June 2009), 341-345. D01: 10.1089/cpb.2008.0226

[29] Kate Raynes-Goldie. 2010. Aliases, creeping, and wall cleaning: Understanding privacy in the age of Facebook. First Monday 15, 1 (January 2010). D0I: 10.5210/fm.v15i1.2775

[30] Denise Anthony, Celeste Campos-Castillo and Christine Horne. 2017. Toward a Sociology of Privacy. Annu Rev. Sociol., 43, 17,1-21. D0l: https://doi.org/10.1146/annurev-soc-060116053643

[31] Christian Fuchs. 2011. Towards an alternative concept of privacy. Journal of Information, Commun. and Ethics in Society 9, 4 (September 2011), 220-237. D0l: https://doi.org/10.1108/14779961111191039 
[32] Richard Wilk. 2018. Internet Privacy Hogwash. Anthropology News (May 2018). Retrieved August 20, 2018 from http://www.anthropology-news.org/index.php/2018/05/30/internet-privacy-hogwash/.

[33] Mariek M.P. Vanden Abeele, Ralf De Wolf and Rich Ling. 2018. Mobile media and social space: how anytime, anyplace connectivity structures everyday life. Media and Commun. 6, 2 (May 2018), 5-14. D0I: http://dx.doi.org/10.17645/mac.v6i2.1399

[34] Alice E. Marwick and Danah boyd. 2011. I Tweet honestly, I tweet passionately: Twitter users, context collapse, and the imagined audience. New media \& society 13, 1 (July 2010), 114-133. D0l: $10.1177 / 1461444810365313$

[35] Jessica Vitak. 2012. The Impact of Context Collapse and Privacy on Social Network Site Disclosures. Journal of Broadcasting $\&$ Electronic Media 56, 4 (December 2012), 451-470. D0l: 10.1080/08838151.2012.732140

[36] Annette N. Markham. 2013. Remix culture, remix methods: Reframing qualitative inquiry for social media contexts. In N. Denzin and M. Giardina (eds.), Global Dimensions of qualitative Inquiry. Left Coast Press, Walnut Creek, CA.

[37] Susan Barnes. 2006. A Privacy paradox: Social networking in the United States. First Monday 11, 9 (September 2006), 1-10. D0l: https://doi.org/10.5210/fm.v11i9.1394.

[38] Jose Van Dijck. 2014. Datafication, dataism and dataveilance: Big Data between scientific paradigm and ideology. Surveillance \& Society12, 2 (May 2014), 197-208. D0l: https://doi.org/10.24908/ss.v12i2.4776

[39] Erich Goode and Nachman Ben-Yahuda. 1994. Moral panics: The social construction of deviance. Blackwell, Oxford, UK.

[40] W. James Potter. 2013. Review of Literature on Media Literacy. Sociology Compass 7, 6 (June 2013), 417435. DOI:

$10.1111 /$ soc 4.12041

[41] Leo Van Audenhove, Ilse Mariën and Hadewijch Vanwynsberghe. 2018. Media Literacy Policy in Flanders Belgium: From Parliamentary Discussions to Public Policy. Journal of Media Literacy Education 10, 1 (January 2018), 59-81.

[42] Lucy L. Henke. 1999. Children, advertising, and the Internet: An exploratory study. In D. W Schumann and Esther Thorson (eds.), Advertising and the World Wide Web. Psychology Press, New York, NY.

[43] John Palfrey and Urs Gasser. 2008. Born Digital: Understanding the first generation of digital natives. Perseus Books Group, New York, NY.

[44] Seounmi Youn. 2005. Teenagers' perceptions of online privacy and coping behaviors: a risk-benefit appraisal approach. Journal of Broadcasting \& Electronic Media 49, 1 (June 2010), 86-110. D0l: https://doi.org/10.1207/s15506878jobem4901_6

[45] Seounmi. Youn. 2009. Determinants of Online Privacy concern and Its Influence on Privacy Protection Behaviors Among Young Adolescents. Journal of Consumer Affairs 43, 3 (September 2009), 389-418. D0I: https://doi.org/10.1111/j.1745-6606.2009.01146.x

[46] New York Magazine. 2018. Kids, the Internet, and the End of Privacy. Retrieved December 2018 from: http://nymag.com/news/features/27341/ 
[47] Paul Hodkinson. 2017. Bedrooms and beyond: Youth, identity and privacy on social network sites. New media \& society 19, 2 (September 2015), 272-288. D0I: 10.1177/1461444815605454

[48] Bridgette Wessels. 2012. Identification and the practices of identity and privacy in everyday digital communication. New media $\&$ society 14, 8 (July 2012), 1251-1268. D0I: https://doi.org/10.1177/1461444812450679

[49] Grant Blank, Gillian Bolsover and Elizabeth Dubois. 2014. A New Privacy Paradox: Young people and privacy on social network sites. Global Cyber Security Capacity Centre: Draft Working Paper. (August 2014), 34 pages. DOI: 10.2139/ssrn.2479938

[50] Irwin Altman. 1975. The environment and social behavior: Privacy, personal space, territory, crowding. Brooks/Cole, Monterey, CA.

[51] Sandra Petronio. 2002. Boundaries of Privacy: Dialectics of Disclosure. State University of New York Press, Albany, NY.

[52] Caroline Lancelot Miltgen and Dominique Peyrat-Guillard. 2014. Cultural and generational influences on privacy concerns: a qualitative study in seven European countries. European Journal of Information Systems 23, 2 (March 2014), 103-125. Dol: https://doi.org/10.1057/ejis.2013.17

[53] Alyson Leigh Young and Anabel Quan-Haase. 2013. Privacy protection strategies on Facebook: The internet privacy paradox revisited. Information, Commun. \& Society 16, 4 (April 2013), 479-500. D0I: 10.1080/1369118X.2013.777757

[54] Petter Bae Brandtzaeg, Marika Lüders and Jan Havard Skjetne. 2010. Too Many Facebook "Friends"? Content Sharing and Sociability Versus the Need for Privacy in Social Network Sites. International Journal of Human-Computer Interaction 26, 11-12 (November 2010), 1006-1030. D01: https://doi.org/10.1080/10447318.2010.516719

[55] Reyman Rob, Ralf De Wolf and Pierson Jo. 2014. Evaluating social media privacy settings for personal and advertising purposes. Info 16, 4, 18-32. D0I: https://doi.org/10.1108/info-01-2014-0004

[56] Alcinda Honwana. 2012. The time of youth: work, social change and politics in Africa. Kumarian Press, Sterling, Virgina.

[57] Sunaina Maira and Elisabeth Soep. 2005. Youthscapes: The popular, the national, the global. Penn Press, Philadelphia, Pennsylvania.

[58] Julian Sefton-Green. 1998. Introduction: Being young in the digital age. In J. Sefton-Green (eds.), Digital diversions: Youth culture in the age of multimedia. University College London Press, London, UK.

[59] Mizuko Ito and Daisuke Okabe. 2005. Intimate Connections: Contextualizing Japanese youth and mobile messaging. In: R. Harper, L. Palen, and A. Taylor (eds.), The Inside Text. The Kluwer international series on computer supported cooperative work (vol. 4). Springer, Dordrecht, The Netherlands.

[60] Gerard Goggin and Kate Crawford. 2011. Generation disconnections: Youth culture and mobile communication. In R. Ling and S. W. Campbell (eds.), Mobile communication: Bringing us together or tearing us apart? Transaction, New Brunswick, NJ.

[61] Alice Marwick and Danah Body. 2018. Understanding Privacy at the Margins: Introduction. International Journal of Commun. 12, (February 2018), 1157-1165. D0I: 1932-8036/20180005 
[62] Payal Arora and Laura Scheiber. 2017. Slumdog romance: Facebook love and digital privacy at the margins. Media, Culture \& Society 39, 3 (April 2017), 408-422. D0I: 10.1177/0163443717691225

[63] Elisabetta Locatelli. 2017. Images of Breastfeeding on Instagram: Self-Representation, Publicness, and Privacy Management. Social Media + Society, (May 2017), 1-14. D0I: 10.1177/2056305117707190

[64] Lara Fulenwieder and Adam Molnar. 2018. Settler governance and privacy: Canada's Indian Residential School Settlement Agreement and the mediation of state-based violence. International Journal of Commun., 12, (February 2018), 1332-1349. Retrieved from https://ijoc.org/index.php/ijoc/article/view/7042

[65] Ellie Rennie, Tyson Yunkaporta and Indigo Hocombe-James. 2018. Privacy Versus Relatedness: Managing Device Use in Australia's Remote Aboriginal Communities. International Journal of Commun., 12, (February 2018), 1291-1309. Retrieved from https://ijoc.org/index.php/ijoc/article/view/7051/2299

[66] Alice Marwick, Diego Murgia Diaz and John Palfrey. 2010. Youth, Privacy and Reputation: Literature Review. Berkman center for Internet \& Society at Harvard University, (March 2010), 82 pages. Retrieved February 8, 2019 from https://clalliance.org/wpcontent/uploads/files/YouthPrivacyReputationBERKMAN.pdf

[67] Helena Wulff. 1995. Introducing youth culture in its own right: the state of the art and new possibilities. In H. Wulff and A. T. Vered (eds.), Youth Cultures: a cross-cultural perspective. Routledge, New York, NY.

[68] Petter B. Brandtzaeg and Marika Lüders. 2018. Time Collapse in Social Media: Extending the Context Collapse. Social Media + Society, (March 2018). DOI: https://doi.org/10.1177/2056305118763349

[69] Susan C. Herring. 2008. Questioning the generational divide: Technological exoticism and adult construction of online youth identity. In D. Buckingham (eds.), Youth, identity, and digital media. MIT Press, Cambridge, MA.

[70] Fenshu, Liu. 2010. The norm of the 'good' netizen and the construction of the 'proper' wired self: The case of Chinese urban youth. New media \& society 13, 1 (May 2010), 7-22. D0I: 10.1177/1461444809360701

[71] Harry Blatterer. 2010. The Changing Semantics of Youth and Adulthood. Cultural Sociology 4, 1 (March, 2010), 63-79. D0l: https://doi.org/10.1177/1749975509356755

[72] Sabine Kurtenbach. 2014. Postwar Violence in Guatemala: A mirror of the Relationship between Youth and Adult Society. Int. Journal of Conflict and Violence 8, 1, 119-133. D0I: 10.4119/UNIBI/ijcv.285

[73] Michael Herzfeld. 2014. Serendipitous Sculpture: Ethnography does as Ethnography goes. Anthropology and Humanism 39, 1 (June 2014), 3-9. D0l: https://doi.org/10.1111/anhu.12031 